\title{
Em busca de um devir performativo queer em Portugal
}

\author{
João M. Diniz Ferreira
}

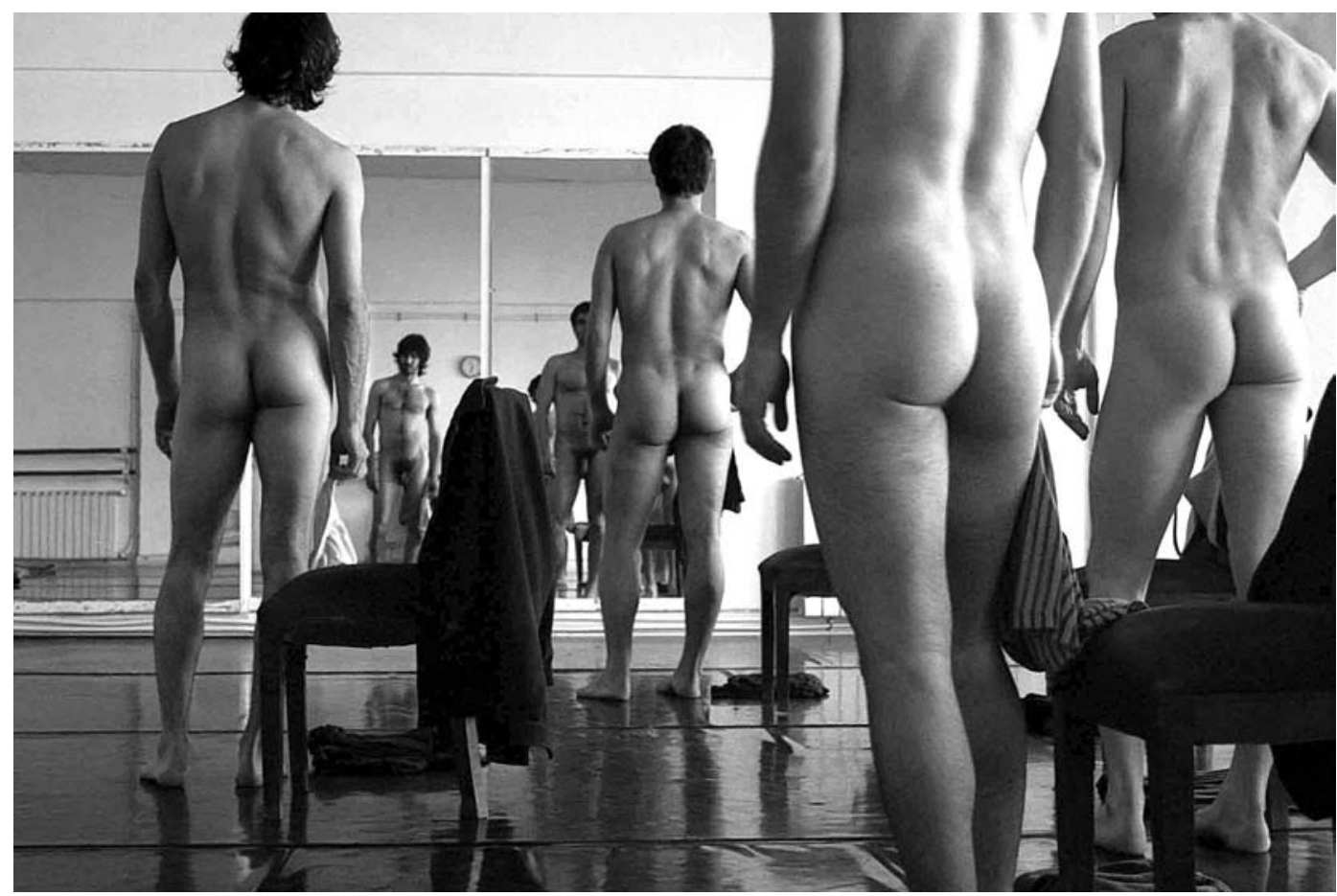

Corpo de baile, dir. Miguel Pereira, 0 Rumo do Fumo, 2005, fot. Cláudia Mateus.

A discussão em torno da génese e do estabelecimento do conceito de performance está longe de ser pacífica. Nos últimos anos, muito tem vindo a ser escrito sobre o assunto, seja na academia, em programas de espectáculos, nas revistas ou em livros da especialidade. A análise da performance pede um certo enquadramento teórico e descritivo, ainda mais importante se o objecto de investigação se relacionar com a subcategoria designada como performance queer. Em Portugal, a resistência a esta especificação performativa tem caracterizado a academia e os próprios criadores, prejudicando seriamente o processo de legitimação crítica do objecto que tal conceito procura descrever. Já na prática artística, é justo reconhecermos que esta resistência tem sido pontualmente quebrada.

De uma forma lata, podemos dizer que a performance está intimamente ligada ao pós-modernismo e às formas do pensamento pós-estruturalista. Novas teorizações e concepções de poder, apoiadas em estudos étnicos e raciais, sexuais ou de género, abrem hoje espaço para uma redefinição do corpo e do sujeito, repensando as suas relações com o histórico e o artístico. 0 corpo, enquanto superficie regulada por um poder político, é uma topografia debilitada, na medida em que é construída segundo os interesses de um sistema regulador ligado a concepções hegemónicas de representação heterossexual. Segundo Judith Butler, este principio de coerência parece querer forçar a normalização das descontinuidades na construção do género, venham elas dos corpos gay, lésbico, bissexual ou transgénero, pois, em rigor, nem o género deriva do sexo, nem o desejo e a sexualidade derivam do género (Butler 1999: 392). A perturbação que estes corpos produzem no sistema normativo heterossexual denuncia precisamente a contingência da sua normatividade hegemónica, a ponto de expor a sua artificialidade constitutiva.

0 teatro, à semelhança de outras produções culturais, pode ser o lugar, não só de afirmação pessoal e colectiva, mas de reivindicação dos direitos de indivíduos e grupos especialmente sujeitos à pressão do corpo único admitido pela sociedade. 0 teatro vem sendo inclusive um lugar privilegiado para a construção e consolidação de identidades sexuais dissidentes. As experiências estéticas propostas pelo teatro interagem sempre com as mudanças ideológicas ligadas às noções de género e de sexualidade. Foi aliás na transição dos anos 50 para os anos 60, particularmente nos Estados Unidos da América, que assistimos à formação de uma linguagem teatral 
alternativa, integrando também influências europeias. Entre estas, destacaria o trabalho teórico de Artaud, mas também a divulgação e pesquisa de novas estéticas teatrais desenvolvidas por encenadores como Bertolt Brecht, pelas vanguardas russas e pelas linguagens performativas de carácter mais interventivo, antecipadas pelos movimentos futurista e surrealista. Refiram-se ainda o universo revelado pela dramaturgia do absurdo e, com destaque especial, dois nomes europeus, ambos determinantes na pesquisa e na formação de actores: Peter Brook e Jerzy Grotowski.

Mas outros factores se conjugaram para a emergência de uma vanguarda teatral nas décadas referidas. Os novos espaços de representação, como os grandes armazéns semi-abandonados e as galerias de arte (locais privilegiados no estabelecimento da performance art), propõem uma nova dinâmica comunicativa e atraem públicos com um perfil diferenciado. Um conjunto significativo de criadores acaba assim por propor e/ou aderir a experiências tão diversas como o agit-prop, o teatro-ritual, o teatro-dança, o teatro antropológico ou o teatro terapêutico. Já em finais dos anos cinquenta, frequentemente no espaço das galerias de arte, criadores como Allan Kaprow, Jim Dine ou Claes Oldenburg apresentam happenings, nos quais o corpo surgia como parte integrante da instalação/objecto exposto. A dupla John Cage e Merce Cunningham desenvolve uma fusão entre concerto musical, dança e performance. A par dos happenings e das acções do grupo Fluxus, estas práticas abrem caminho, entre outras experiências, à dança pós-moderna Americana. Trisha Brown, Yvonne Rainer, Steve Paxton, Lucinda Childs e Meredith Monk aproximam a dança da linguagem das artes plásticas, através do recurso a acções e a objectos do quotidiano, defendendo mesmo a "democratização" do corpo na dança, ainda que certos artistas abandonem a narratividade em favor da abstraç̧ão do movimento.

A relação entre a performance art e as artes plásticas, juntamente com os espectáculos visuais de Bob Wilson e as exibições singulares de Laurie Anderson, tornam cada vez mais difícil a distinção entre artes visuais e teatro, ou mesmo entre teatro e concerto musical. Segundo Sally Banes, terá sido com a entrada de criadores ligados ao teatro e à dança neste espaço híbrido da performance art que o termo gradualmente se vê associado às artes performativas (Banes 1998:6). Assim, em meados dos anos oitenta, a performance art emancipa-se progressivamente dos museus e das galerias de arte, ocupando espaços alternativos, mais próximos do entretenimento, alterando as suas características, na medida em que os afasta de um discurso intelectual, tornando-se mais acessivel em termos formais e conceptuais. A generalização destas práticas provocou o esbatimento da fronteira entre performance art e teatro.

Segundo David Román, foi no contexto que acabo de sintetizar que o termo performance - sem a partícula art - emergiu, como uma tentativa de distinguir algo como um subgénero, derivação tardia da performance art, mas relacionado com um trabalho de raiz mais comunitária (Román 1998:120). A apropriação do termo performance por parte dos próprios criadores ter-se-á devido, em muito, a uma tentativa de fuga a uma categorização academizante dos seus trabalhos, enquadrando-os nos estudos sobre teatro ou nos estudos estritamente dedicados às artes plásticas. Se a performance art, devido à sua ligação às artes plásticas, se centra em questões formais e de valor estético, a performance, na acepção de Román, não se deixa dominar pelos princípios estéticos, investindo essencialmente nas questões da comunidade e da identidade, adquirindo, deste modo, uma conotação mais politica.

Em Portugal, talvez devido à inexistência de um forte sentido cívico, social, cultural ou de um associativismo político de grande expressão ou influência, parecem nunca terem sido criadas as condições necessárias para o estabelecimento de uma performance queer portuguesa, nem sequer de uma cultura da performance. E quando algo sucede não tem a força, a coerência e sentido de comunidade (política, social, artistica) comparável às situações vividas noutros lugares. Existe, no entanto, um conjunto de actos isolados, de tentativas de inscrição e de percursos artísticos que merecem atenção. João Grosso, em 1998, apresentou o que se revelaria como uma tentativa de inscrição deste género no seio da própria comunidade gay, num espectáculo apresentado na sede da ILGA, o Centro Comunitário Gay e Lésbico de Lisboa. Refiro-me a 0 ano do pénis. 0 que poderia fazer antever 0 desenvolvimento de um género performativo de cariz interactivo, interventivo e comunitário, aproveitando ao máximo o próprio contexto físico (e político) em que estava inserido, revelou-se apenas um (nobre) acto isolado. 0 espectáculo, colando textos de Derek Jarman, Camille Paglia, Edmund White, entre outros, revela o objectivo simultaneamente político e sexual da proposta performativa em causa. Como o próprio João Grosso explicitava em texto incluído no programa, intitulado "Um pénis duro \&t teso", aquela performance pretendia ser mais do que um "comício-conferência" centrado na temática do pénis. E quem assistiu a este espectáculo sabe que o que aconteceu naquele tempo e naquele espaço foi, acima de tudo, um acto político. Apesar de a temática da sexualidade ser já recorrente nos últimos trinta anos, segundo o encenador/performer, verifica-se ainda uma falsa benevolência (mesmo no meio artístico, aparentemente mais tolerante), persistindo a hipocrisia. No mesmo texto, João Grosso estende a problemática ao próprio conceito queer: "Por que há-de haver um grupo restrito de gays ou de lésbicas, etc. e não se mistura tudo?". Só "revelando o pénis" é que se poderia despoletar o confronto entre as culturas minoritárias e a chamada cultura mainstream. Num acto performativo isolado, João Grosso conseguiu resumir num só espectáculo alguns dos pressupostos principais da performance: o agit-prop, a política sexual e as pretensões comunitárias. 


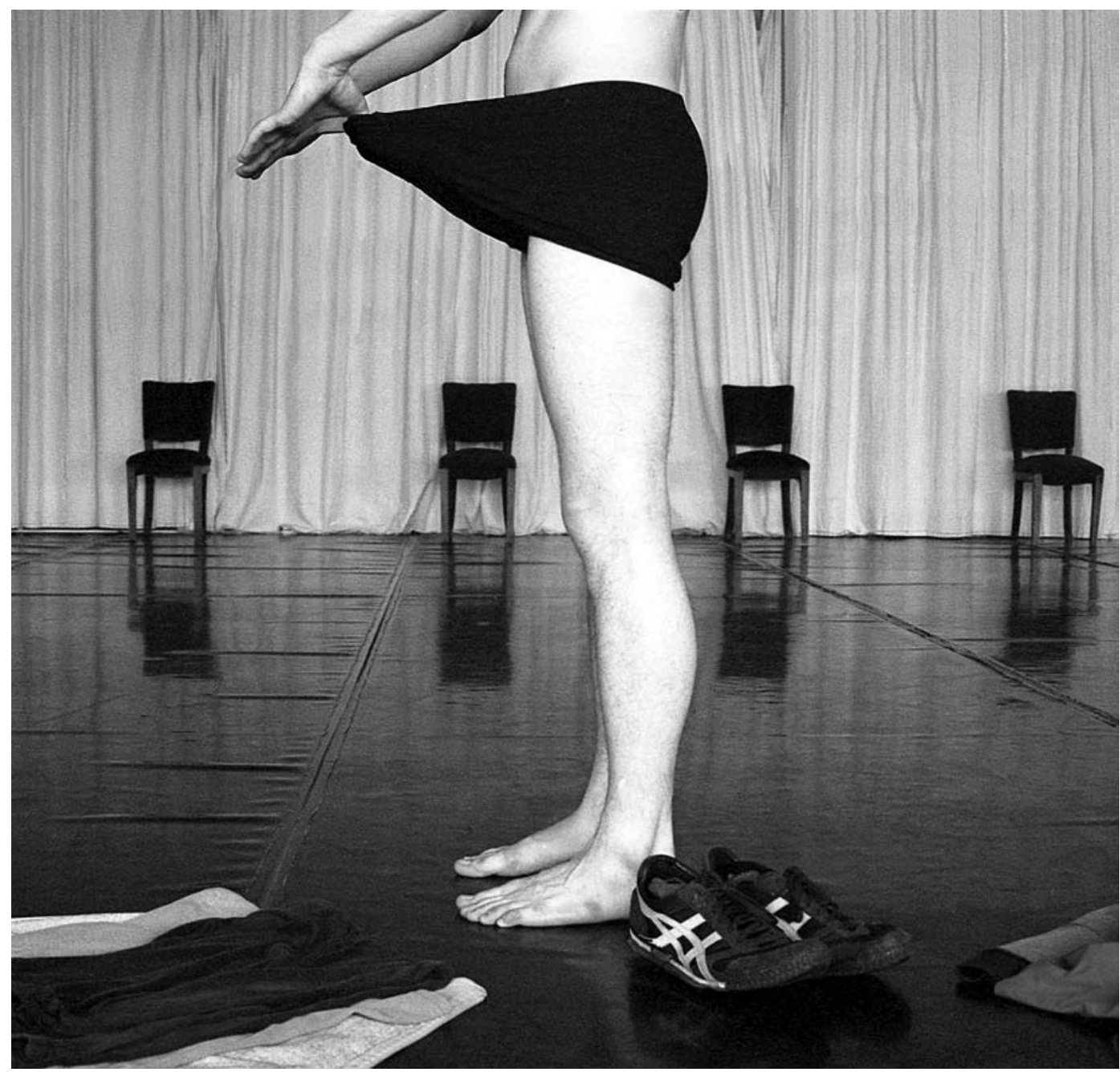

Corpo de baile,

dir. Miguel Pereira,

0 Rumo do Fumo, 2005

(Andreas Dyrdal),

fot. Cláudia Mateus.

Embora neste caso especifico a escolha do local tenha sido pensada de acordo com a natureza e objectivos do espectáculo, na história recente das artes performativas em Portugal, a questão dos espaços teatrais acabou por se revelar fundamental na própria dramaturgia e nas propostas formais de muitos espectáculos. Trata-se de uma marca central da performance. A questão da escolha "dramatúrgica" do espaço de apresentação, um aspecto que no nosso país (na verdade, em muito devido às próprias restrições económicas das companhias ou criadores isolados), acabou por se transformar num quase-género performativo. Veja-se o exemplar caso de 0 Olho, nomeadamente os espectáculos situados no enorme armazém do Ginjal; ou os vários espaços da Galeria ZDB, em Lisboa, os quais acolheram durante anos várias performances de criadores nacionais, bem como de nomes consagrados além fronteiras, como é o caso de Annie Sprinkle.

Num coerente percurso de criação e de profundas raizes no conceito de performance art, assumindo a relação entre performance e artes plásticas (algo que o encenador designará como perfinst), o percurso de Luis Castro temse revelado talvez o mais consistente quanto a uma eventual performance queer em Portugal. Explorando

constantemente o género e a sexualidade, Luis Castro não teme a exposição explícita do corpo (e do género) dos performers, a que junta um forte cunho de "portugalidade", mormente quando cruza as memórias pessoais com as memórias ligadas à história recente da descolonização, como foi o caso do triptico MoçAmor (Mur, Ral e Elo), realizado em 1999. 0 mesmo sucede quando Castro recupera alguma da dramaturgia portuguesa mais permissiva a uma leitura queer, como é o caso de 0 pecado de João Agonia e de António marinheiro, de Bernardo Santareno, em espectáculos apresentados respectivamente em 1998 e 2002.

Numa outra vertente, também o percurso de Mónica Calle se tem revelado coerente na exploração e no questionamento da identidade e do género. 0 poder e as políticas sexuais são o tema subterrâneo de criações exemplares de Calle, como Os dias que nos dão (2000, sobre texto de Luis Fonseca) O bar da meia-noite (2000, a partir de Eu vi o Epidauro, de Fiama Hasse Pais Brandão) ou As lágrimas amargas de Petra von Kant (2001, sobre texto de Rainer Werner Fassbinder). Em qualquer destes espectáculos, Mónica Calle faz da proximidade entre espectador e performers um elemento quase incómodo para ambas as partes, obrigando ambos a uma sobre-exposição mútua. Estes são alguns aspectos que permitem a análise das suas criações sob o prisma da performance queer.

Mas um dos planos mais expressivos deste género entre nós acabou por resultar da fusão entre o teatro e a dança, algo habitual na tradição performativa. 0 movimento português da nova dança foi e continua a ser um dos terrenos mais férteis no que diz respeito à pesquisa da identidade e do género, tendo como matéria central o 
próprio corpo do performer. Neste contexto, vale a pena destacar o espectáculo Corpo de baile, de Miguel Pereira.

Formado pela Escola Superior de Dança, Miguel Pereira trabalhou como intérprete para diversos coreógrafos e encenadores (Francisco Camacho, Jerôme Bel, Jorge Silva Melo). Em Junho de 2005, estreia na Culturgest o espectáculo Corpo de baile. Esta performance reúne exemplarmente uma série de pressupostos que aqui venho levantando. Já em António Miguel - trabalho que Ihe valeu, em 2000, o Prémio Revelação José Ribeiro da Fonte e uma Menção Honrosa por parte do Prémio Acarte / Maria Madalena Azeredo Perdigão -, Miguel Pereira explorava a nudez como veículo privilegiado de exposição, constituindo uma espécie de autobiografia do corpo, fora de pressupostos sociais e culturais. Neste espectáculo, dois corpos dominam o espaço cénico, ensaiando a união num só, numa sequência de espelhos, encenando o desdobramento do Eu no Outro.

Mas foi em Corpo de baile que Miguel Pereira levou mais longe o pressuposto da "democratização" do corpo, uma das bandeiras do pensamento pós-moderno nas artes performativas, especialmente presente no movimento da nova dança. Se em António Miguel os corpos no espelho pareciam reflectir a união do Eu/Outro, em Corpo de baile celebra-se a diversidade dos corpos, as suas assimetrias, a impossibilidade frequente da sincronia entre os corpos, não por impossibilidade dos performers, mas pelas suas

Programa de próprias marcas físicas. Não é o traje enquanto marca

o ano do pénis, social e de identidade que diferencia os sujeitos: as roupas por Gonçalo Diniz, 1998. que vestem são semelhantes, no mesmo registo fashion e uniforme tipo H\&tM. A diferença é, sim, marcada pela nudez dos corpos e pelas diferenças que os separam, contudo, unindo-os. É perante a nudez dos performers que percebemos a incapacidade de sincronizar o movimento. Um corpo nu é muito mais vulnerável à detecção de falhas e de "particularidades", como refere Miguel Pereira no programa do espectáculo. Este corpo não nos aparece filtrado pelas cores e tecidos das roupas, pela luz que estas reflectem ou por uma qualquer ilusão "vestida" de conjunto, tapando as diferenças.

A ideia de que a performance é um acto pertencente ao nosso quotidiano e algo relacionado com a forma como nos apresentamos perante os outros, como cumprimos os rituais diários ou como executamos a nossa própria encenação social (e de género), é um mote exaustivamente explorado nesta performance. A insistência no acto de vestir e despir revela o que em tal acto pode ser universal e particular. A criação de Miguel Pereira mostra como somos uma massa social uniforme e como quem está de fora (nu), pode destoar e inclusive passar pelo ridículo - uma das sequências mais bem conseguidas do espectáculo acontece precisamente quando o performer António Tagliarini surge nu entre os outros todos uniformizados, em busca de uma peça de roupa, na esperança de também poder pertencer.

Em Corpo de baile é central a ideia do corpo (nu) enquanto território de individualidade, mas também enquanto último reduto na afirmação de políticas sexuais.
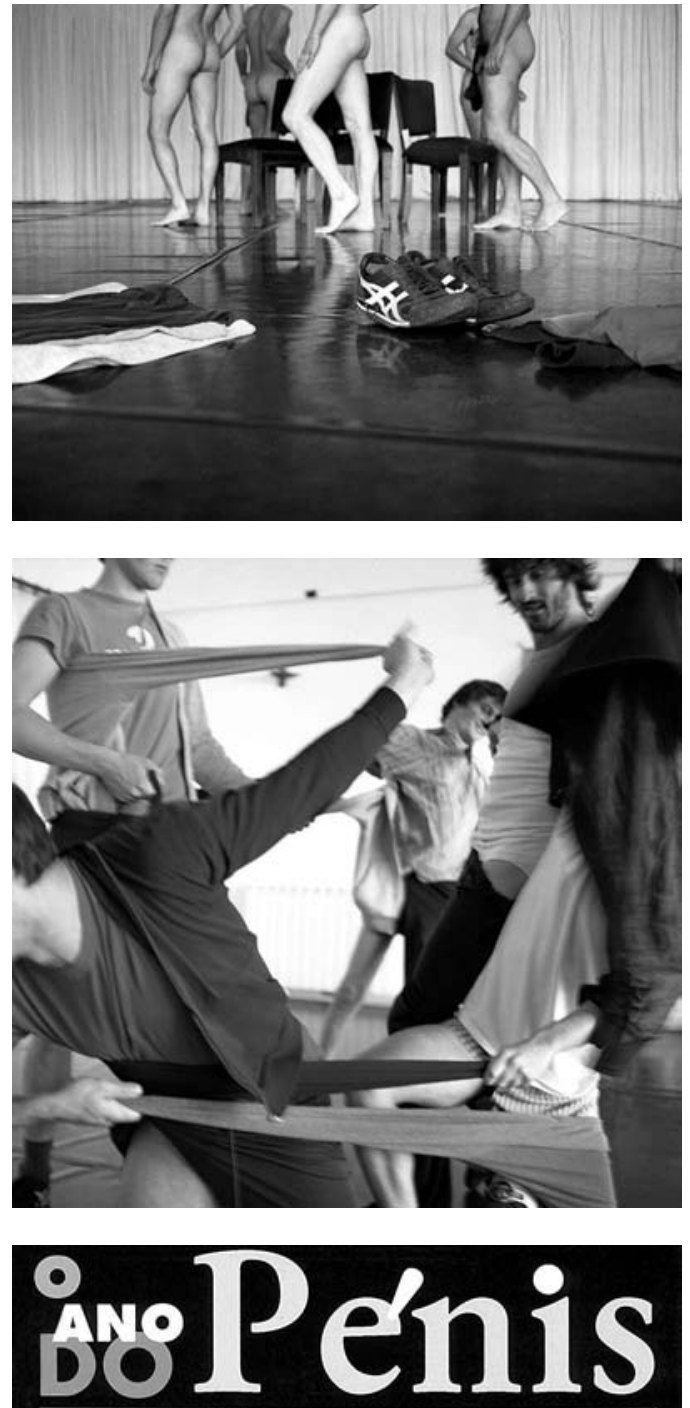

Um Espectáculo de João Grosso

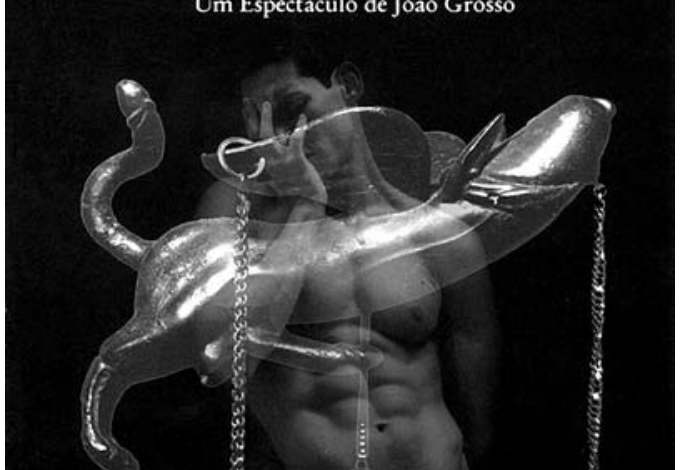

Este corpo feito arma mostra-nos assim o que a própria performance tem de mais afirmativo na cena artística.

\section{Referências bibliográficas}

BANES, Sally (1998), Subversive Expectations: Performance Art and Paratheater in New York (1976-85), Ann Arbor, University of Michigan Press.

BUTLER, Judith (1999), "From Interiority to Gender Performatives", in Fabio Cleto (ed.), Camp: Queer Aesthetics and the Performing Subject, Ann Arbor, University of Michigan Press.

ROMÁN, David (1998) Acts of Intervention: Performance, Gay Culture, and AIDS, Bloomington and Indianapolis, Indiana University Press. 